\title{
PENGELOLAAN BANK SAMPAH BERKELANJUTAN DI WILAYAH PERDESAAN KABUPATEN BANTUL
}

\author{
Bambang Suwerda $^{1}$, Su Rito Hardoyo ${ }^{2)}$, Andri Kurniawan ${ }^{3)}$ \\ ${ }^{122) 3)}$ Program Studi Doktor Ilmu Lingkungan ,Sekolah Pasca Sarjana Universtas Gadjah Mada Yogyakarta
}

\begin{abstract}
Abstrak
Pengelolaan bank sampah di perdesaan Kabupaten Bantul saat ini banyak yang tidak aktif dan hanya sekitar 25\% yang masih berjalan. Tujuan penelitian ini untuk meneliti faktor-faktor intensi mengelola bank sampah yang berkelanjutan di wilayah perdesaan Kabupaten Bantul. Sampel penelitian adalah penabung sampah di bank sampah wilayah perdesaan Kabupaten Bantul. Data dianalisis menggunakan análisis jalur. Hasil penelitian menunjukkan terdapat hubungan yang signifikan antara peran Pemerintah dan penggiat sampah yang tergabung dalam Jejaring Pengelola Sampah Mandiri (JPSM) dengan partisipasi masyarakat menabung sampah di bank sampah. Pengetahuan, partisipasi, peran pemerintah dan JPSM memiliki hubungan signifikan dengan intensi perilaku mengelola sampah di bank sampah. Studi ini membantu memahami kekuatan hubungan relatif dari faktor determinan intensi mengelola bank sampah berkelanjutan. Kekuatan hubungan paling besar adalah antara peran pemerintah dan JPSM dengan intensi, diikuti hubungan peran dengan partisipasi, kemudian antara partisipasi dengan intensi, dan yang paling lemah adalah hubungan antara pengetahuan dengan intensi perilaku mengelola sampah di bank sampah.
\end{abstract}

Kata Kunci: Bank sampah berkelanjutan, faktor determinan, partisipasi masyarakat

\begin{abstract}
The management of waste banks in rural areas of Bantul Regency are currently many inactive, and only $25 \%$ active. The aim of this research is to research the intention factors of sustainable waste bank management in the rural area of Bantul. The research sample were waste savers in the waste bank of the rural area of Bantul Regency. Data were analyzed using path analysis. The results of the study show that there is a significant relationship between the role of the Government and waste activists who are members of the Independent Waste Manager Network (IWMN) with community participation in waste banks. Knowledge, participation, the role of the government and JPSM have a significant relationship with the intention of sustainable waste banks management behaviour. This study helps understand the strength of the relative relationship of the determinants of intention to manage a sustainable waste bank. The strength of the biggest relationship is between the role of government and JPSM with intentions, followed by role relationships with participation, then between participation and intention, and the weakest is the relationship between knowledge and intention.
\end{abstract}

Keywords: Determinant factor, management of sustainable saste banks, public participatory

\section{PENDAhULUAN}

Data dari DLH Kabupaten Bantul tahun 2016, jumlah sampah di Kabupaten Bantul adalah $229.929 \mathrm{~m}^{3} /$ hari dengan rata-rata tiap orang menghasilkan 0,0025 $\mathrm{m} 3 /$ hari Timbulan sampah terus bertambah., dengan jumlah penduduk Kabupaten Bantul saat ini 935.000 jiwa, dan rata-rata tiap orang menghasilkan $0,5 \mathrm{~kg} / \mathrm{hari}$, maka tiap hari dihasilkan sampah 467,5 ton/hari. Upaya Dikirim/submitted: 6 November 2018

Diterima/accepted: 26 Desember 2018 
pengurangan sampah perlu terus dilakukan dan salah satu caranya adalah dengan membangun bank sampah. Bank sampah adalah sistem pengelolaan sampah rumah tangga dengan cara dipilah dan ditabung di bank sampah yang dibuktikan dengan adanya buku rekening tabungan sampah (Suwerda, 2012)

Kelompok pengelola sampah mandiri dengan sistem bank sampah di wilayah Kabupaten Bantul tahun 2016 sebanyak 127 bank sampah dimana 25 bank sampah berjalan aktif dan 102 bank sampah tidak aktif/ mati suri (Suwerda, 2012) Pengelolaan bank sampah yang berkelanjutan menegaskan perlunya perubahan paradigma dari kumpul- angkut-buang menjadi pengelolaan yang bertumpu pada pengurangan dan penanganan sampah. Pengelolaan sampah dengan bank sampah pada dasarnya merubah perilaku dari membuang dan membakar sampah menjadi memilah dan menabung sampah. Menurut Ajzen (1991) intensi seseorang terhadap perilaku pengelolaan sampah berkelanjutan diukur melalui 3 determinan, yaitu sikap individu, tekanan sosial yang dirasakan untuk menerapkan perilaku, dan persepsi seseorang terhadap kontrol yang dimilikinya terkait perilaku tersebut. Keberadaan bank sampah di perdesaan tidak lepas dari partisipasi masyarakat dan pihak pemerintah setempat. Pembentukan perilaku pengelolaan sampah di bank sampah yang berkelanjutan pada masyarakat berorentasi pada pembangunan berkelanjutan yang dapat menjadi role of model bagi perilaku masyarakat dalam mengelola sampah di bank sampah terutama wilayah perdesaan. Hubungan antara pengetahuan, partisipasi, peran dengan intasi mengelola bank sampah berkelanjutan merupakan permasalahan yang ingin diperoleh jawabannya dalam penelitian ini.

\section{METODE PENELITIAN}

Jenis penelitian ini termasuk penelitian survei dengan pendekatan cross sectional dimana data seluruh variabel penelitian dikumpulkan pada waktu yang sama. Data yang dihasilkan dianalisis secara deskriptif dan analitik menggunakan analisa jalur (path analysis).

Sampel penelitian adalah 100 penabung sampah yang diambil dengan teknik multi stage random sampling. Stage pertama dipilih 9 bank sampah di 9 kecamatan wilayah perdesaan, yaitu Bank Sampah Karang Asri Imogiri, Bank Sampah Sumber Rejeki Jetis, Bank Sampah Muda Harapan Bambanglipuro, Bank Sampah Pringgading Lestari Pajangan, Bank sampah Giat Barokah Pleret, Bank Sampah SJR Blink Sedayu, Bank Sampah Muda Harapan Piyungan, Bank Sampah Berkah 
Pundong, dan Bank Sampah Ngabean Berseri Pandak. Stage kedua dipilih sampel secara proporsional dari setiap bank sampah. Alat dalam penelitian ini adalah alat tulis, kamera, kuesioner, peta, GPS, komputer, dan sofware.

Data penelitian terdiridari data primer dan data sekunder. Data primer yaitu penabung sampah, pengelola bank sampah, sementara data sekunder yaitu kajian referensi, literatur, dan standarisasi yang menyangkut tentang pengelolaan sampah dengan sistem bank sampah..Teknik pengambilan data menggunakan wawancara, dokumentasi, observasi, kuesioner. Variabel penelitian adalah pengetahaun, partisipasi, peran pemerintah, peran JPSM terhadap intensi perilaku mengelola bank sampah berkelanjutan. Skala penelitian yang digunakan adalah skala likert. Analisa secara analitik menggunakan análisis jalur (path analysis) untuk menemukan faktor determinan yang paling besar dalam pengelolaan bank sampah berkelanjutan di wilayah perdesaan Kabupaten Bantul.

\section{HASIL DAN PEMBAHASAN}

Pengelola bank sampah di wilayah perdesaan dengan penggerak utama sebagai pengelola adalah ibu-ibu PKK. Rata-rata cakupan pelayanan bank sampah di perdesaan adalah skala dusun dan belum menjadi kegiatan pokok dan bersifat sukarela. Waktu pelayanan rata rata seminggu sekali dimana hari dan jam sesuai kesepakatan warga. Pembeli sampah sebagai mitra bank sampah rata-rata terdapat satu pembeli sampah di setiap bank sampah. Jenis sampah yang diterima antara lain sampah kertas, kaleng/botol/logam, dan sebagian sampah plastik, terdapat satu leader di setiap bank sampah di perdesaan, Bank sampah yang ada saat ini mulai terjalin jejaring komunikasi antar bank sampah di tiap wilayah perdesaan yang ditunjukkan adanya jejaring pengelola sampah mandiri di tiap desa.

Indikator bank sampah berkelanjutan antara lain tingkat pengetahuan masyarakat terhadap bank sampah, partisipasi masyarakat terhadap bank sampah yang ditunjukkan jumlah dan jenis sampah yang mereka tabung, niat/intensi perilaku menabung sampah, peran pemerintah baik teknik maupun non teknis, dan peran jejaring pengelola sampah mandiri (JPSM).

Model analisis jalur bank sampah di wilayah perdesaan Kabupaten Bantul disajikan pada Gambar 1. Setelah dilakukan uji hipotesis diperoleh hasil nilai chi-square sebesar 0,008 dengan derajat bebas 1 dan p-value sebesar 0,929 lebih dari alpha (0,05) sehingga hipotesis awal 
diterima maka dapat kesimpulan bahwa model fit, dalam arti model yang dibangun sudah cocok dengan data dan dapat digunakan.

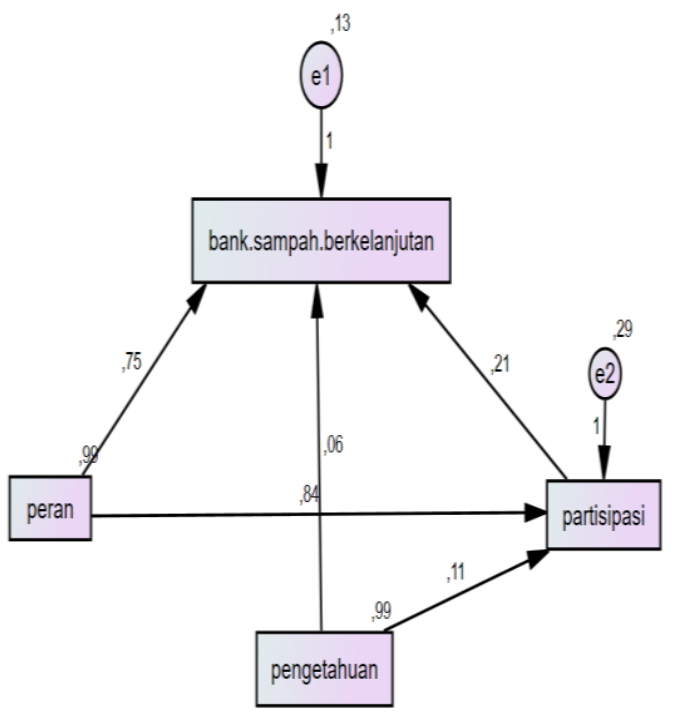

Gambar 1. Model Jalur untuk Bank Sampah di Wilayah Perdesaan Kabupaten Bantul

Estimasi parameter dan nilai dari model jalur bank sampah di wilayah perdesaan Kabupaten Bantul disajikan pada Tabel 1. di bawah

Tabel 1. Estimasi Parameter dan Nilai dari Model Jalur Bank Sampah di Wilayah Perdesaan Kabupaten Bantul

\begin{tabular}{ccccccc}
\hline Endogen & & Eksogen & Estimate & S.E. & C.R. & P \\
\hline partisipasi & $\leftarrow$ & Peran & 0,836 & 0,054 & 15,428 & $* * *$ \\
\hline partisipasi & $\leftarrow$ & Pengetahuan & 0,114 & 0,054 & 2,111 & 0,035 \\
\hline $\begin{array}{l}\text { bank.sampah. } \\
\text { berkelanjutan }\end{array}$ & $\leftarrow$ & Pengetahuan & 0,056 & 0,037 & 1,506 & 0,132 \\
\hline $\begin{array}{l}\text { bank.sampah. } \\
\text { berkelanjutan }\end{array}$ & $\leftarrow$ & Partisipasi & 0,205 & 0,067 & 3,054 & 0,002 \\
\hline $\begin{array}{l}\text { bank.sampah. } \\
\text { berkelanjutan }\end{array}$ & $\leftarrow$ & Peran & 0,752 & 0,067 & 11,268 & $* * *$ \\
\hline
\end{tabular}

Tabel 1 menunjukkan estimasi parameter beserta nilai standard error (S.E.), construct reliability (C.R.), dan p-value (P). Kolom estimate menunjukkan nilai loading factor. Nilai loading factor yang semakin besar menunjukkan pengaruh yang semakin besar. Variabel peran memiliki 
loading factor 0,752 dibandingkan pengetahuan dan partisipasi dalam mempengaruhi bank sampah berkelanjutan sehingga peran memberikan pengaruh yang paling besar terhadap bank sampah berkelanjutan. Kolom standard error menunjukkan nilai error pada suatu variabel eksogen yang mempengaruhi variabel endogen. Kolom construct reliability menunjukkan nilai konsistensi. Nilai construct reliability yang lebih besar dari 0,7 menunjukkan bahwa variabel tersebut konsisten. Pada kolom tersebut terlihat bahwa semua nilai construct reliability > 0,7 sehingga sudah konsisten. Kolom p-value dapat digunakan untuk melihat apakah variabel eksogen mempengaruhi variabel endogen secara signifikan atau tidak. Semakin kecil nilai pvalue maka semakin signifikan dalam mempengaruhi. Tanda *** menunjukkan bahwa nilai $\mathrm{p}$ value sangat kecil mendekati nol.

Analisis kelayakan model jalur (Goodness of Fit) untuk bank sampah di wilayah perdesaan Kabupaten Bantul : AGFI (1,000), CFI (1,000), RMSEA (0,000). Kelayakan dan kebaikan dari sebuah model untuk digunakan dapat dinilai dari beberapa kriteria. Kriteria yang digunakan pada penelitian ini adalah AGFI, CFI, dan RMSEA.

Nilai indeks keselarasan yang disesuaikan (Adjusted Goodness of Fit Index (AGFI)) dengan ketentuan nilai AGFI sama dengan atau lebih besar dari 0,9. Jika nilai lebih besar dari 0,9 maka model mempunyai kesesuaian model keseluruhan yang baik. Pada model perdesaan memiliki nilai AGFI yang telah lebih besar dari 0,9.

Indeks Kecocokan Komparatif (Comparative Fit Index (CFI)) dengan nilai antara 0 - 1 dengan ketentuan jika nilai mendekati angka 1 maka model yang dibuat mempunyai kecocokan yang sangat tinggi sedang jika nilai mendekati 0, maka model tidak mempunyai kecocokan yang baik. Terlihat bahwa nilai CFI untuk model perdesaan memiliki nilai yang mendekati 1, sehingga model tersebut memiliki kecocokan yang baik.

Kesalahan kuadrat rata-rata akar (Root mean square error of approximation, RMSEA), disebut juga RMS atau RMSE dan juga perbedaan per derajat kebebasan (degree of freedom). Didasarkan pada konvensi, ada kecocokan model yang baik jika RMSEA besarnya lebih kecil atau sama dengan 0,05. ada kecocokan model yang cukup jika besarnya RMSEA kurang dari atau sama dengan 0,08. Penemuan yang terbaru, Hu dan Bentler (1999) menyarankan besarnya 
RMSEA $\leq$ 0,06 merupakan titik potong untuk sebuah kecocokan model yang baik. Model pedesaan memiliki kecocokan model yang baik karena nilai RMSEA yaitu $0,000 \leq 0,06$.

Dasar pemikiran dari penelitian ini adalah untuk memindai dan mengamati faktor-faktor determinan dari intensi perilaku pengelolaan bank sampah yang berkelanjutan dan juga untuk memastikan kekuatan relatif dari masing-masing faktor determinan yang terdiri atas pengetahuan, partisipasi masyarakat, peran Pemerintah dan JPSM. Penelitian ini juga membahas hubungan pengetahuan masyarakat tentang bank sampah dengan partisipasi menabung sampah di bank sampah, hubungan antara peran Pemerintah dan JPSM dengan partisipasi masyarakat dalam menabung sampah di bank sampah. Hasil yang diperoleh dari model struktural menunjukkan $a$ good of fit (kecocokan) berdasarkan nilai goodness of fit yang dihasilkan di wilayah perdesaan.

Berdasarkan hasil penelitian pada kolom estimate menunjukkan nilai loading factor. Nilai loading factor yang semakin besar menunjukkan pengaruh yang semakin besar. Variabel peran memiliki loading factor yang lebih tinggi dibandingkan pengetahuan dan partisipasi dalam mempengaruhi bank sampah berkelanjutan di wilayah perdesaan sehingga peran pemerintah dan JPSM memberikan pengaruh yang paling besar terhadap keberlanjutan bank sampah di perdesaan kabupaten bantul.

Hasil penelitian ini menyatakan bahwa pengetahuan masyarakat tentang bank sampah berhubungan dan berkontribusi positif dengan partisipasi masyarakat di wilayah perdesaan. Hasil ini sejalan dengan temuan yang diperoleh oleh Gusti dkk (2015) yang menyatakan bahwa pengetahuan tentang pengelolaan sampah berkelanjutan berhubungan dan berkotribusi positif dengan sikap terhadap pengelolaan sampah berkelanjutan. Pengetahuan responden tentang bank sampah menjadi variabel yang penting untuk menjaga keberlangsungan bank sampah. Masyarakat selama ini hanya tahu tentang bak sampah sebagai tempat membuang sampah dengan dicampur, sementara pengetahuan masyarakat tentang bank sampah perlu terus ditingkatkan untuk meningkatkan partisipasi mereka.

Partisipasi masyarakat menjadi hal yang penting dalam mengelola sampah melalui bank sampah. Masyarakat dapat berpartisipasi dalam berbagai bentuk kegiatan. Bentuk partisipasi masyarakat di bank sampah antara lain partisipasi sebagai pengelola bank sampah, yang dapat membuat 
keputusan-keputusan strategis bersama pengelola lain, partisipasi dalam pelaksanaan kegiatan di bank sampah mulai dari pelayanan nasabah, administrasi, pemilahan, dan penjualan sampah, atau sebagai penabung sampah, partisipasi dalam pemanfaatan hasil dari bank sampah seperti mendapatkan uang hasil tabungan sampah yang mereka tabung, dan partisipasi dalam monitoring evaluasi bank sampah dengan memberikan masukan yang terkait kemajuan bank sampah.. Bank sampah adalah salah satu kegiatan yang bersifat sosial di masyarakat untuk meningkatkan partisipasi masyarakat mengelola sampah.

Pengetahuan masyarakat tentang bank sampah dapat diperoleh dari berbagai sumber seperti sosialisasi oleh DLH Bantul dan JPSM Bantul, serta yang diperoleh melalui media cetak, radio dan televisi yang berpengaruh besar dalam pembentukan opini dan kepercayaan tentang bank sampah. Informasi baru tentang sesuatu memberikan landasan kognitif bagi peningkatan pengetahuan (Azwar, 2011 dalam Setyowati dan Mulasari, 2013). Komunikasi dan upaya pendidikan untuk meningkatkan pengetahuan tentang pengelolaan sampah melalui bank sampah telah efektif dalam mendorong partisipasi masyarakat mengelola sampah. Keterlibatan masyarakat dalam pengelolaan bank sampah memberikan optimisme untuk meningkatkan partisipasi masyarakat mengelola sampah (Hasfarm dkk., 2014). Pengetahuan tentang bank sampah diukur dengan lima indikator yang terdiri dari pengetahuan tentang mengurangi sampah, memilah sampah, memanfaatkan sampah, mendaur ulang sampah, dan menabung sampah.

Temuan penelitian ini menyatakan semakin baik pengetahuan masyarakat tentang bank sampah maka semakin tinggi partisipasi masyarakat terhadap pengelolaan bank sampah yang berkelanjutan. Perlu upaya yang intensif dan berkesinambungan dari pihak Pemerintah dan Pengelola JPSM untuk meningkatkan pengetahuan masyarakat tentang bank sampah yang berkelanjutan ini dengan memasukkannya sebagai materi pokok dalam sosialisasi pengelolaan sampah yang sering dilakukan oleh DLH Kabupaten Bantul.

Sosialisasi untuk meningkatkan pengetahuan tentang bank sampah dapat dilakukan dengan cara mendatangi kegiatan yang dilakukan masyarakat seperti kegiatan arisan ibu-ibu PKK, pertemuan pemuda pemudi/karang taruna, pengajian, arisan bapak-bapak, ataupun mengundang perwakilan masyarakat untuk menghadiri kegiatan sosialisasi bank sampah yang dilaksanakan oleh pemerintah desa atau kecamatan. Upaya peningkatan pengetahuan dapat juga dilaksanakan 
dengan mengoptimalkan peran media cetak maupun elektronik seperti radio televisi, koran, majalah, penyebaran leaflet bank sampah. Kegiatan sosialisasi tidak hanya sekali, akan tetapi secara berkala dilakukan, sehingga masyarakat akan semakin meningkat pengetahuannya tentang bank sampah. Materi yang minimal diketahui oleh masyarakat tentang bank sampah adalah Pengertian bank sampah, konsep dasar bank sampah, komponen bank sampah, instrumen/kelengkapan bank sampah, cara mendirikan bank sampah, manfaat bank sampah, Pengetahuan jenis-jenis sampah, pengetahuan tentang cara mendaur ulang sampah plastik, pengetahuan tentang cara mengelola sampah organik, hambatan dalam pengelolaan bank sampah, cara mengatasi masalah di bank sampah.

Hasil penelitian ini menyatakan bahwa pengetahuan tentang bank sampah berhubungan dan berkontribusi positif dengan intensi perilaku pengelolaan bank sampah berkelanjutan. Temuan ini sejalan dengan asumsi teoritis dalam teori perilaku berencana yang dikembangkan oleh Ajzen, 1991 dalam Gusti dkk., 2015, yang menjelaskan intensi perilaku yang merupakan anteseden terdekat dari perilaku, bahwa intensi/niat perilaku seseorang menjadi penentu apakah seseorang akan melakukan atau tidak melakukan perilaku tertentu. Ada 3 determinan untuk mengukur intensi perilaku seseorang terhadap perilaku pengelolaan sampah berkelanjutan : Sikap individu terhadap perilaku pengelolaan sampah berkelanjutan, Seberapa besar tekanan social yang dirasakan untuk menerapkan perilaku tersebut (norma subyektif), dan persepsi terhadap kontrol yang dimilikinya sehubungan dengan perilaku tersebut yang disebut sebagai perceived behavioral control (PBC).

Bank sampah adalah media untuk belajar memilah sampah. Hal ini sebagai suatu media untuk membiasakan masyarakat memilah sampah, karena mereka mencampur sampah yang mereka hasilkan di dalam bak sampah, dan hal ini sejalan dengan penelitian Kumar (2012), dimana dengan alasan masyarakat sehari-hari sibuk, mereka menyampur sampah untuk dibuang di bak sampah. Selain adanya upaya membiasakan memilah dan menabung sampah, bank sampah juga memiliki nilai ekonomi terutama dari hasil tabungan sampah, dan ini sejalan dengan pendapat dari UNEP (2005), dimana dalam pengelolaan sampah perlu ditekankan pentingnya circulair economi untuk menjaga nilai tambah dalam proses produksi. 
Hasil penelitian ini menyatakan bahwa peran Pemerintah dan JPSM berhubungan dan berkontribusi positif dengan partisipasi masyarakat di bank sampah. Upaya DLH Kabupaten Bantul terhadap peningkatan pengetahuan yang berpengaruh terhadap partisipasi masyarakat di bank sampah, dengan melakukan sosialisasi di tiap desa di wilayah Kabupaten Bantul. Hal ini terus dilakukan untuk membangun kesadaran pentingnya mengelola sampah, karena kesadaran masyarakat adalah sebagai faktor kunci di bank sampah. Selain melakukan sosialisasi, pemerntah dalam hal ini DLH Bantul maupun Pemerintah desa wajib menyediakan sarana prasaraa pengelolaan sampah, dan perlu melakukan sinkronisasai APBDES dengan APBD dimana terdapat butir yang mencantumkan pengelolaan sampah. Perlu ditekankan bahwa sampah menjadi tanggung jawab setiap orang. Pedekatan dapat dilakuan melalui organisasi sosial, tokoh masyarakat dan tokoh agama. Program groyok sampah di TPS Liar yang dilakukan oleh DLH Bantul yang bekerjasama dengan Pemerintah Desa, dan JPSM AMOR Kabupaten Bantul dimaksudkan untuk membangun kesadaran masyarakat agar tidak membuang sampah secara sembarangan, mewujudkan lingkungan yang bersih dan bebas sampah, dan setelah digropyok pemantauan lokasi menjadi tanggung jawab desa setempat untuk pengelolaan TPS liar tersebut.

Hasil penelitian ini selaras dengan temuan peneliti sebelumnya dari Jesicca Mc Allister (2015) yang menyatakan bahwa diperlukan upaya kesadaran bagi masyarakat dalam pengelolaan sampah berkelanjutan di negara berkembang. Hasil penelitian di India yang dilakukan oleh Arif dkk (2012) menyatakan bahwa terjadi peningkatan kesadaran dalam pengelolaan sampah. Secara keseluruhan model yang menggunakan kerangka teori perilaku berencana mampu menjelaskan intensi perilaku pengelolaan sampah berkelanjutan dengan pendekatan yang baik dengan cara sederhana dan memadai. Hal ini sejalan dengan penelitian Saxena dkk (2010) terdapat bebarapa pendekatan yang mempengaruhi keberlanjutan pengelolaan sampah, yaitu pendekatan teknologi, pendekatan institusi, dan pendekatan keuangan/anggaran, dimana salah satu upaya untuk meminimalkan anggaran dalam pengelolaan sampah yang berkelanjutan adalah dengan mendorong partisipasi masyarakat dalam mengelola sampah.

Faktor intensi perilaku atau niat mengelola bank sampah berkelanjutan memiliki 6 variabel yaitu niat hidup sehat, niat lingkungan bersih, niat untuk mendapatkan penghasilan, ajaran agama, 
adanya peraturan/hukuman, dan budaya/kebiasaan.. Pendekatan yang paling cocok untuk pengembangan bank sampah adalah yang memiliki skor pada variabel terbesar atau dengan kata lain memiliki nilai rata-rata variabel yang paling besar. Intensi pengelolaan bank sampah berkelanjutan di wilayah perdesaan Kabupaen Bantul disajikan pada Tabel 2 dan Gamba 2.

Tabel 2. Intensi Pengelolaan Bank Sampah Berkelanjutan Wilayah Perdesaan Kabupaten Bantul

\begin{tabular}{lc}
\hline \multicolumn{1}{c}{ Variabel } & Rata-Rata \\
\hline Niat hidup sehat & 7.38 \\
\hline $\begin{array}{l}\text { Niat lingkungan } \\
\text { bersih }\end{array}$ & 8.28 \\
\hline $\begin{array}{l}\text { Niat untuk } \\
\text { mendapatkan } \\
\text { penghasilan }\end{array}$ & 7.38 \\
\hline Ajaran agama & 7.25 \\
\hline $\begin{array}{l}\text { Adanya } \\
\text { peraturan/hukuman }\end{array}$ & 7.56 \\
\hline Budaya/kebiasaan & 8.31 \\
\hline
\end{tabular}

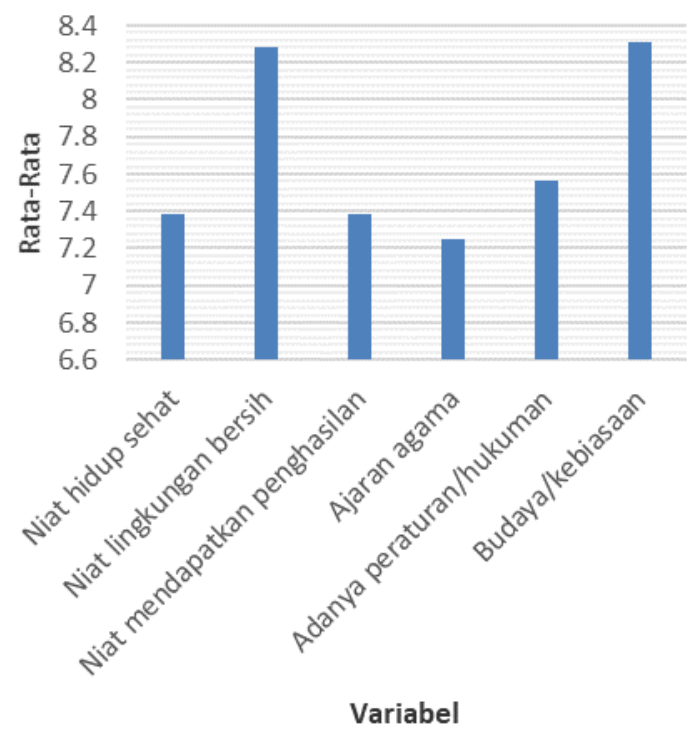

Gambar 2. Grafik Intensi Perilaku Mengelola Sampah di Bank Sampah Wilayah Perdesaan Kabupaten Bantul 
Berdasarkan data hasil penelitian tentang tingkat pengetahuan, partisipasi, peran JPSM dan pemerintah, dan intensi perilaku bank sampah yang berkelanjutan yang berkorelasi positif di wilayah perdesaan. Hal ini menjadi modal yang penting untuk mengembangkan model pengelolaan sampah dengan bank sampah yang berkelanjutan. Keinginan untuk hidup sehat, lingkungan bersih, mendapatkan penghasilan, karena ajaran agama, dan adanya peraturan/hukum, serta budaya/kebiasaan untuk memilah dan menabung sampah menjadi faktor intensi perilaku keberlangsungan bank sampah, dan faktor untuk merubah kebiasaan/budaya merupakan faktor dengan nilai terbesar. Hal ini sejalan dengan hasil penelitian Sarah Elsaid dan El-Houssaine Aghezzaf (2015) dimana dalam model pengelolaan sampah, untuk mencapai keberlanjutan sistem pengelolaan sampah perlu tiga faktor utama, ekonomi, sosial dan lingkungan, yang secara efisien diintegrasikan dan dikelola. Merubah kebiasaan masyarakat dalam mengelola sampah dari membakar dan mencampur serta membuang sampah sembarang menjadi memilah dan menabung sampah merupakan bagian dari aspek sosial dalam pengelolaan sampah.

Keterbatasan anggaran yang ada di DLH Bantul dalam pengadaan sarana dan prasarana bank sampah yang dikembangkan masyarakat perdesaan menjadi permasalahan tersendiri. yang juga dialami oleh kota Karu Naswara Nigeria. Menurut Anyanwu dan Adefila (2014) beberapa kendala dalam pengelolaan sampah di Karu Nasawara antara lain peralatan terbatas, pendanaan yang kurang, personal terbatas, sikap/persepsi yang rendah dari masyarakat terkait pengelolaan sampah.

Model yang menggunakan kerangka teori perilaku berencana secara keseluruhan mampu menjelaskan intensi pengelolaan bank sampah yang berkelanjutan. Berdasar teori perilaku berencana, model yang disusun peneliti apabila dilakukan dengan pendekatan yang baik, dan cara yang sederhana, dan memadai maka model tesebut dapat dikembangkan di wilayah perdesaan Kabupaten Bantul.

\section{KESIMPULAN}

Berdasarkan hasil analisis jalur (path analysis), terdapat dua hubungan yang signifikan yaitu antara pengetahuan dengan partisipasi masyarakat serta pengetahuan dengan intensi perilaku mengelola sampah di bank sampah wilayah perdesaan Kabupaten Bantul 
Sehubungan dengan pengembangan bank sampah berkelanjutan di perdesaan Kabupaten Bantul, maka pemerintah dan JPSM memegang peranan paling tinggi dalam meningkatkan partisipasi masyarakat. Model pengembangan bank sampah yang berkelanjutan di wilayah perdesaan Kabupaten Bantul dilakukan dengan terus meningkatkan pengetahuan, partisipasi, intensi perilaku masyarakat menabung sampah serta meningkatkan peran JPSM dan Pemerintah.

Hasil penelitan ini memberikan rekomendasi kepada Pemerintah Kabupaten Bantul untuk menyusun perencanaan pengembangan bank sampah wilayah perdesaan dengan meningkatkan peran JPSM dan Pemerintah setempat. Pengelola JPSM AMOR Kabupaten Bantul perlu melakukan sosialisasi terbentuknya bank sampah berbasis masyarakat perdesaan, yang berkoordinasi dengan Pemerintah dalam teknis pelaksanaan bank sampah, dan dalam mendampingi masyarakat untuk membentuk bank sampah.

\section{DAFTAR PUSTAKA}

Anyanwu, N.C dan Adefila, J.O. (2014). Nature and Management of Solid Waste in Karu Nasarawa State Nigeria. American International Journal of Conteporary Research, 4 (11), pp. 149-159

Ajzen, I. (1991). The Theory of Planned Behaviour. Organizational Behaviour and Human Decision Processes, 50 (22), 179 - 211

Arif, M., Bendi, D., Toma-Sabbagh, T. and Sutrisna, M. (2012). Construction waste management in India: an exploratory study. Construction Innovation, 12 (2), pp. 133-155

BLH Bantul. (2016). Laporan Periodik Per Bulan Sampah Harian Kabupaten Bantul Tahun 2016. Yogyakarta.

DLH Bantul. (2016). Laporan Kinerja Pengelolaan Lingkungan Hidup Daerah Kabupaten Bantul Tahun 2016. Yogyakarta: Pemerintah Kabupaten Bantul.

Elsaid, S. and Aghezzaf, E. (2015). A framework for sustainable waste management: challenges and opportunities. Management Research Review, 38 (10), pp. 1086-1097.

Gusti, A., Isyandi, B., Bahri, S., dan Afandi, D. (2015). Hubungan Pengetahuan , Sikap dan Intensi Perilaku Pengelolaan Sampah Berkelanjutan Pada Siswa Sekolah Dasar di Kota Padang. Dinamika Lingkungan Indonesia, 2, 100-107.

Hasfarm D. Purba, Christia Meidiana, and Dimas W. Adrianto. (2014). Waste Management 
Scenario through Community Based Waste Bank: A Case Study of Kepanjen District, Malang Regency, Indonesia. International Journal of Environmental Science and Development, 5 (2).

Hu, L. \& Bentler, P. (1999). Cutoff criteria for fit indices in covariance structure analysis: conventional criteria versus new alternatives. Structural Equation Modeling, 6, 1-55.

Jesicca Mc Alister. (2015). Factors Influencing Solid-Waste Management in the Developing World. Utah State University

Kumar, B. (2012). Theory of Planned Behaviour Approach to Understand the Purchasing Behaviour for Environmentally Suistainable Product. IIMA Working Papers WP2012-12-08, Indian Institute of Management Ahmedabad, Research and Publication Department.

Saxena, R.K. Srivastava, A.B. Samaddar. (2010). Towards sustainable municipal solid waste management in Allahabad City. Management of Environmental Quality: An International Journal, 21 (3), pp.308-323

Setyowati, R dan Mulasari, S. A. (2013). Pengetahuan dan Perilaku Ibu Rumah Tangga dalam Pengelolaan Sampah Plastik. National Public Health Journal, 7(12), pp 562-566

Suwerda, B. (2012). Bank Sampah Kajian Teori dan Penerapan. Yogyakarta: Pustaka Rihama. UNEP. (2005). Solid Waste Management (1 ${ }^{\text {st }}$ ed.). Cal Recovery Incorporated 